\title{
A Longitudinal Study for the Effect of Vitamin D Adjunct to Chemotherapy on Non-Metastatic Breast Cancer Patients after Mastectomy
}

\author{
Ehab I. Mohamed ${ }^{1 *}$, Azza M. Helal ${ }^{2,3}$, Noha M. Awad ${ }^{4}$, Gihane I. Khalil ${ }^{5}$, Amani M. Bayoumi ${ }^{6}$ and Nadia A. Abd El Moneim
}

*Correspondence: eimohamed@yahoo.com ; ehab.abdo@alexu.edu.eg

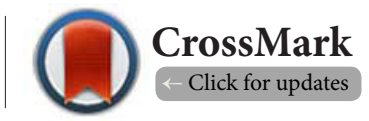

\begin{abstract}
${ }^{1}$ Medical Biophysics Department, Medical Research Institute, Alexandria University, Alexandria, Egypt. 2Physics Department, King Abdulaziz University, Jeddah, Saudi Arabia.

${ }^{3}$ Medical Physics Unit, Radiology and Intervention Department, Faculty of Medicine, Alexandria University, Alexandria, Egypt.

${ }^{4}$ Epidemiology Department, High Institute of Public Health, Alexandria University, Alexandria, Egypt.

${ }^{5}$ Chemical Pathology Department, Medical Research Institute, Alexandria University, Alexandria, Egypt.

${ }^{6}$ Physics Department, Faculty of Science, Alexandria University, Alexandria, Egypt.

${ }^{7}$ Cancer Management and Research Department, Medical Research Institute, Alexandria University, Alexandria, Egypt.
\end{abstract}

\begin{abstract}
Background: Women with $\mathrm{BC}$ are at increased risk for the development of osteoporosis and skeletal fractures. We investigated the effect of CAF chemotherapy alone and adjunct to vitamin $\mathrm{D}$ treatment on biochemical markers of bone formation and on segmental and total bone mineral density (BMD) for non-metastatic breast cancer (NMBC) postmenopausal women who had gone through a mastectomy.

Methods: The study population was comprised of $200 \mathrm{NMBC}$ women who were divided into two equal groups; before and after treatment with CAF chemotherapy alone and before and after treatment with CAF+Vitamin D treatment protocols. Other 100 healthy participants served as the Control group. All participant women were subjected to blood biochemical analysis and segmental and total BMD measurements using Dual-energy X-ray Absorptiometry technique.

Results: We found that CAF chemotherapy alone had no effect on women's body weight, BMI, tumor marker CA15-3, PTH, ALP and Ca levels as compared to the initial state, while CAF+Vitamin D adjunct treatment caused significant reductions in their levels as compared to the initial state and Healthy Controls. We found also that $\mathrm{CAF}$ chemotherapy alone had no effect on plasma levels of $\mathrm{P}$ and Vitamin $\mathrm{D}$ as compared to initial state yet, $\mathrm{CAF}+$ Vitamin $\mathrm{D}$ adjunct treatment caused significant elevations in their levels as compared to the initial state and Healthy Controls.

Conclusions: Vitamin D may decrease the risk of $\mathrm{BC}$ recurrence by decreasing risk factors like body weight and serum levels of CA15-3, PTH, ALP, and Ca, thus increasing segmental and total BMD and decreasing the risk of osteoporosis.
\end{abstract}

Keywords: Vitamin D, Chemotherapy, Breast Cancer, Bone Mineral Density, Osteoporosis, Dual-energy X-ray Absorptiometry

\section{Introduction}

Breast cancer (BC) (i.e., invasive ductal carcinoma, invasive lobular carcinoma, Paget's disease, medullary, mucinous, and inflammatory $\mathrm{BC}$ ) is the most common invasive cancer and the second most common cause of cancer death, after lung cancer, in women worldwide [1,2]. Its estimates amounted a total of 2.1 million each year, causing 627,000 deaths that are approximately $15 \%$ of all cancer deaths among women in 2018 $[2,3]$. According to the National Population-Based Registry Program, BC was the most prevalent cancer among Egyptian women in the period $2008-2011$, representing $15.41 \%$ of total cancer cases with an age-standardized rate of $24.3 / 100,000$ 
Mohamed et al., Breast Cancer Reports 2019,

individuals (32.04\% and 48.8/100,000 for women and $0.51 \%$ and $0.9 / 100,000$ for men; respectively) $[4,5]$.

Prognosis and survival rate of $B C$ patients have been improved considerably, making BC curable cancer, yet with long-term complications in bone health resulting from the treatment given or cancer itself [6]. In fact, chemotherapyinduced menopause, aromatase inhibitors, radiation therapy, and long-term bisphosphonate consumption can all increase bone resorption without a corresponding increase in bone formation [7], resulting in loss of bone mineral density (BMD) [8]. Compared to healthy postmenopausal women who may lose $\sim 1 \%$ of their BMD per year, women with BC lose 2-3 fold more $B M D$, increasing the risk of hip and vertebral fractures, which are associated with a significant decline in function, quality of life, and higher mortality rates [9]. Recently, there has been considerable interest in the potential effects of serum vitamin $D$ [25-hydroxyvitamin $\mathrm{D} ; 25(\mathrm{OH}) \mathrm{D}$ ] concentrations in the etiology of $B C[10]$. Besides the essential role of vitamin $D$ in calcium homeostasis and bone metabolism, vitamin $\mathrm{D}$ can induce cell differentiation, inhibit cell growth and regulate apoptosis in normal and malignant cells, including human $B C$ cells $[11,12]$.

The objectives of this study were to investigate the effect of chemotherapy for a period of 6 cycles adjunct to vitamin $D$ treatment on biochemical markers of bone formation and on segmental and total BMD for non-metastatic breast cancer (NMBC) postmenopausal women who had gone through a mastectomy.

\section{Patients and methods \\ Patients}

The study population was comprised of 300 women and were divided into three groups: women with NMBC $(n=100)$ before and after receiving 6-cycles of a three-drug Cyclophosphamide, Adriamycin, and 5-Fluorouracil (CAF) chemotherapy alone. Women with NMBC $(n=100)$ before and after receiving CAF + Vitamin $D$ treatment protocol. Other 100 apparently healthy women matching for age, weight and socioeconomic level of patient relatives served as the Healthy Control group. Participants were recruited from among patients referred to the Department of Cancer Management and Research, Medical Research Institute, Alexandria University; for diagnosis, treatment, and follow-up. All participants were asked to freely volunteer to the study protocol and to provide a signed informed consent prior to their inclusion in the study. The study protocol was approved by the Ethical Committee of the Medical Research Institute, Alexandria University, Alexandria, Egypt.

Women with NMBC (stage I-III) were diagnosed according to TNM classification [13] after surgery; were investigated before and after vitamin $D$ intramuscular injection of vitamin $D$ (Devarol-S-200.000 I.U. Amp. Memphis for pharmaceuticals \& Chemical Industries) once per month adjunct to chemotherapy for a period of 4 months.

\section{Methods}

All women were subjected to complete history taking and history of previous bone fractures. Age of menopause was determined by self-report. And also the following analyses were performed to all participants using standard methods:

\section{Blood Biochemical Analyses}

Fasting blood samples were collected from all participant women to determine serum levels of CA 15-3 by chemiluminescence technique (Immulite 1000, Siemens Healthcare Diagnostics Inc., Flanders, NJ, USA) [14]; Calcium (Ca) using a semi-automatic chemical analyzer (Olympus AU 400, Olympus Life and Material Science, Europe GmbH, Hamburg, Germany) [15]; Phosphorus (P), Alkaline Phosphatase (ALP) and Parathyroid hormone (PTH) [16]; and Vitamin D [25(OH)D] [17].

\section{Imaging, Body-Composition and Bone Densitometric Measurements}

Imaging studies were carried out for all participant women using Chest X-ray, abdominal and pelvic ultrasound and mammography. Demographic and body-composition variables were also measured for all participant women. Specifically, body weight $(\mathrm{kg}$ ) (participants clothed in underwear, bare feet) was measured using a digital scale sensitive to the nearest $0.01 \mathrm{~kg}$ (Electronic Body Scale, TCS-200-RT, China). Height $(m)$ was measured using a stadiometer. BMI was calculated as Weight $/$ Height $^{2}\left(\mathrm{~kg} / \mathrm{m}^{2}\right)$. Segmental (i.e., head, arms, trunk, ribs, spine, pelvis and legs) and total bone mineral content (BMC) and BMD were assessed using a Dual-energy X-ray Absorptiometry (DXA) total body scanner (Lunar DXP Pro, GE Health Care, USA), as detailed earlier by our group $[18,19]$.

\section{Statistical analysis}

Data were fed to the computer and analyzed using SPSS software package version 20.0 [20]. Qualitative data were described using the number and percent. Quantitative data were described using Range (minimum and maximum), mean, standard deviation (SD) and median. The distributions of quantitative variables were tested for normality using Kolmogorov-Smirnov test, Shapiro-Wilk test, and D'Agstino test if it reveals normal data distribution, parametric tests were applied. If the data were abnormally distributed, non-parametric tests were used. For normally distributed data, a comparison between the three studied groups were analyzed using $F$-test (ANOVA) and post-hoc test (Scheffe) for pair-wise comparisons, also paired $t$-test was used to analyze two paired data. Significance of the obtained results was judged at the $5 \%$ level.

\section{Results}

The study population was comprised of 300 women, who were divided into three groups: women with NMBC (stage I-III) diagnosed according to TNM classification, before $(n=100)$ and after ( $n=97)$ receiving 6-cycles of CAF chemotherapy alone, with a mean age $( \pm S D)$ of $50.08 \pm 11.26$ and range 29.60-71.20 year. Women with NMBC before $(n=100)$ and after $(n=99)$ receiving $\mathrm{CAF}+$ Vitamin $\mathrm{D}$ treatment protocol, with a mean age 
Mohamed et al., Breast Cancer Reports 2019,

$50.93 \pm 10.77$ and range $32.80-64.80$ year. Other 100 apparently healthy women matching for age, weight and socioeconomic level of patient relatives served as the Healthy Control group, with a mean age $48.75 \pm 7.71$ and range 39.10-63.50 year. Demographic characteristics and biochemical parametersfor all study participants are shown in Table 1.

CAF chemotherapy alone had no effect on post-treatment women's body weight, BMI, tumor marker CA15-3, PTH, ALP and Ca levels as compared to pre-treatment state, while CAF + Vitamin D adjunct treatment caused significant $(p<0.05)$ reductions in their post-treatment levels as compared to pretreatment state and Healthy Control group. In the same way CAF chemotherapy alone had no effect on post-treatment plasma levels of $P$ and vitamin $D$ as compared to pre-treatment state yet, CAF + Vitamin D adjunct treatment caused significant $(p<0.05)$ elevations in their post-treatment levels as compared to pre-treatment state and Healthy Control group, Table 1.

CAF chemotherapy alone reduced significantly $(p<0.001)$ segmental (i.e., head, arms, trunk, ribs, spine, pelvis, and legs) and total BMD as compared to pre-treatment state and Healthy Control group, as shown in Figure 1. However, CAF + Vitamin $D$ adjunct treatment was responsible for a significant $(p<0.01)$ post-treatment increase in segmental and total BMD as compared to pre-treatment state.

\section{Discussion}

$\mathrm{BC}$ is the most common cancer, yet albeit the huge progress achieved in its treatment during past decades, it is still the principal cause of cancer death among the female population worldwide $[1,2]$. Vitamin $D$ is one of the critical factors for female reproductive health, which may have protective effects against many cancer types, including $B C[\mathbf{2 1}, \mathbf{2 2}]$. This vitamin is a secosteroid hormone, which regulates the expression of a large number of genes important for female reproduction and health [21]. Low serum levels of vitamin $D$ were found to be common at BC diagnosis with a poor prognosis in terms of overall survival and distant disease-free survival, particularly in postmenopausal females [22]. Vitamin D inhibits the growth of tumor-derived cells from breast, promotes apoptosis in BC cells, and acts as a cancer inhibitor (e.g., enhanced DNA repair, immunomodulation, and protection against antioxidants) $[11,12]$. However, there is a breakdown of vitamin $D$ in tumor cells, causing resistance to the antitumor effects of vitamin $D$ [22]. We found the majority of participant BC women in this study to have vitamin D levels as low as $<32 \mathrm{ng} / \mathrm{ml}$, prior to initiating CAF chemotherapy, findings which are similar to recent pooled analysis of three trials showing that $B C$ risk is markedly higher with serum vitamin $D$ concentrations $<20$ $\mathrm{ng} / \mathrm{ml}[10]$.

Body weight and $\mathrm{BMI}$ of $\mathrm{BC}$ patients did not differ with $\mathrm{CAF}$ chemotherapy after mastectomy, while CAF + Vitamin D adjunct treatment caused a significant $(p<0.001)$ reduction in their levels, as compared to the initial state and Healthy Controls, Table 1. The main effect of the active vitamin $D$ metabolite $1,25(\mathrm{OH})_{2} \mathrm{D}$ is to tonic the body making it tighter and to stimulate the absorption of $\mathrm{Ca}$ from the gut increasing BMD significantly [23]. In line with this, individual segmental and total BMD data showed significant elevations after CAF + Vitamin $D$ adjunct treatment making their values comparable to Healthy Controls, Figure 1.

Our results showed that CA15-3 levels did not differ after CAF chemotherapy, yet decreased significantly $(p<0.001)$ with $C A F+$ Vitamin $D$ adjunct supplementation. Patients with high levels of CA15-3 have a significantly worse prognosis with BC recurrence than those with low levels [24]. It showed also that PTH levels increased significantly $(p<0.001)$ after chemotherapy, but decreased significantly $(p<0.001)$ with $C A F+V i t a m i n$ $D$ adjunct supplementation treatment, thus increasing $B C$

Table 1. Demographic characteristics and blood biochemical parameters assayed for non-metastatic breast cancer (NMBC) women before and after receiving 6-cycles of a three-drug Cyclophosphamide, Adriamycin, and 5-Fluorouracil (CAF) chemotherapy alone; before and after receiving CAF + Vitamin D treatment protocol; and Healthy Control women.

\begin{tabular}{llllll}
\hline & CAF Alone & \multicolumn{3}{l}{ CAF + Vitamin D } & Healthy Control \\
\cline { 2 - 5 } & Before $(n=100)$ & After $(n=97)$ & Before $(n=100)$ & After $(n=99)$ & $(\boldsymbol{n}=\mathbf{1 0 0})$ \\
\hline Age (year) & $50.08 \pm 11.26$ & $50.72 \pm 11.92$ & $50.93 \pm 10.77$ & $51.54 \pm 11.41$ & $48.75 \pm 7.71$ \\
Height $(\mathrm{m})$ & $1.57 \pm 0.05$ & $1.58 \pm 0.05$ & $1.54 \pm 0.06$ & $1.55 \pm 0.06$ & $1.61 \pm 0.06$ \\
Weight $(\mathrm{kg})$ & $83.15 \pm 9.37$ & $85.12 \pm 8.62$ & $81.79 \pm 8.79$ & $72.54 \pm 9.20^{*}$ & $83.11 \pm 7.08$ \\
Body Mass Index (BMI, kg/m $\left.{ }^{2}\right)$ & $33.25 \pm 2.40$ & $34.90 \pm 2.13$ & $34.98 \pm 2.88$ & $30.31 \pm 2.74^{*}$ & $32.06 \pm 2.95$ \\
Tumor Marker CA15-3 (CA15-3, U/ml) & $45.65 \pm 7.71$ & $46.25 \pm 8.03$ & $44.10 \pm 8.61$ & $31.24 \pm 7.92^{*}$ & $19.38 \pm 8.50$ \\
Parathyroid Hormone (PTH, pg/ml) & $61.27 \pm 7.39$ & $84.37 \pm 8.97^{\star}$ & $65.96 \pm 8.98$ & $54.82 \pm 8.50^{*}$ & $61.67 \pm 7.31$ \\
Alkaline Phosphatase (ALP, U/l) & $87.65 \pm 14.05$ & $95.42 \pm 14.38$ & $86.65 \pm 9.53$ & $61.75 \pm 9.38^{*}$ & $68.45 \pm 7.35$ \\
Calcium (Ca, mg/dl) & $9.14 \pm 0.32$ & $9.01 \pm 0.38$ & $9.36 \pm 0.34$ & $8.57 \pm 0.39^{*}$ & $9.36 \pm 0.37$ \\
Phosphorus (P, mg/dl) & $3.75 \pm 0.55$ & $3.89 \pm 0.46$ & $3.98 \pm 0.56$ & $4.56 \pm 0.55^{*}$ & $3.50 \pm 0.57$ \\
Vitamin D[25(OH)D, ng/dl] & $9.69 \pm 2.05$ & $9.73 \pm 2.80$ & $9.65 \pm 2.95$ & $49.14 \pm 2.25^{*}$ & $13.08 \pm 2.36$ \\
\hline
\end{tabular}

Values are expressed as mean $\pm \mathrm{SD}$.

Statistical analysis using Paired $t$-test for comparing between Before and After and post-hoc test (Scheffe) of ANOVA versus Healthy Control women at ${ }^{*} p<0.05$. 


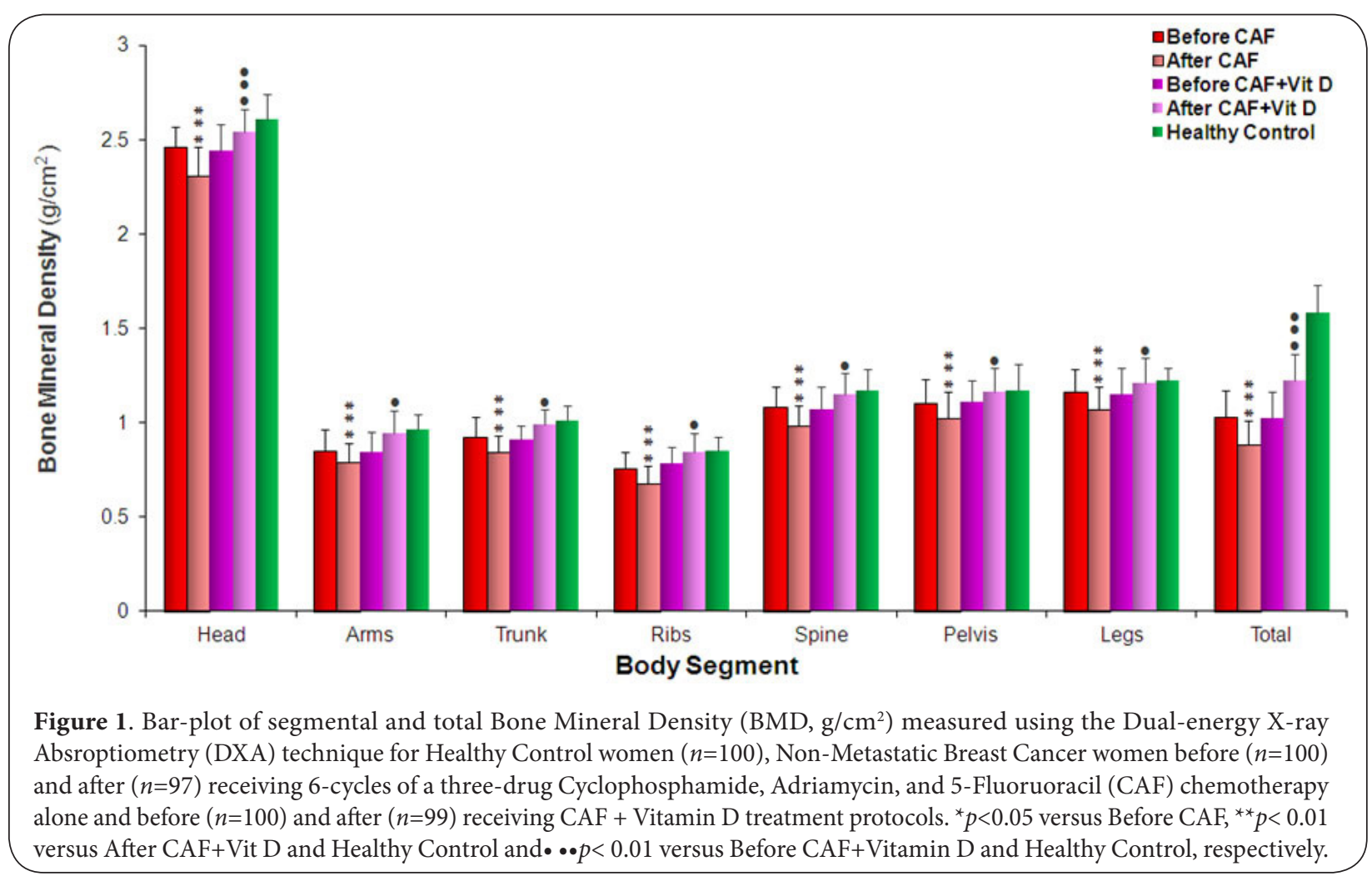

survival. It had been suggested that PTH may be associated with a high risk of $B C$ due to carcinogenic and tumor-promoting effects [25]; such as regulating angiogenesis and osteoclastogenesis in bone metastasis by BC cells [26].

ALP increased significantly $(p<0.05)$ after CAF chemotherapy, but when adjunct to vitamin $D$ treatment, it caused a significant reduction in its levels, which is considered a healthy sign, since ALP is a bone turnover marker. Elevated serum ALP level is considered an essential marker for the diagnosis of vitamin $D$ deficiency, where vitamin $D$ deficiency was diagnosed accidentally on the basis of elevated ALP levels [27]. More to add, physicians, have long recognized that elevated ALP in cancer patients usually signifies that the disease has spread to their bones. However, primary cancers in various organs can generate ALP elevations in the absence of metastasis [28]. CA15-3 was a better predictor of $B C$ recurrence than ALP alone, but the use of both biomarkers together provided a better early indicator of recurrence. Elevated BC tumor marker CA15-3, in conjunction with ALP, was found to be associated with an increased chance of early recurrence in $B C$ [29].

CAF chemotherapy alone reduced significantly $(p<0.001)$ segmental (i.e., head, arms, trunk, ribs, spine, pelvis, and legs) and total BMD as compared to the initial state and Healthy Controls, as shown in Figure 1. However, CAF + Vitamin D adjunct treatment was responsible for a significant $(p<0.05)$ increase in segmental and total BMD as compared to the initial state. Vitamin $D$ deficiency is associated with second- ary hyperparathyroidism, which results in increased bone resorption, the release of $\mathrm{Ca}$ from bones, and may precipitate or exacerbate osteoporosis with consequent ill effects on BMD. Osteopenia and osteoporosis in BC patients were found primarily due to early menopause and vitamin D deficiency and later amplified by chemotherapy and endocrine therapy, particularly the aromatase inhibitors [7]. Thus, BC patients must undergo a baseline metabolic bone evaluation with serum vitamin $\mathrm{D}$ levels and $\mathrm{BMD}[\mathbf{7 , 8 ]}$.

Previous findings suggest an increased incidence and more aggressive $\mathrm{BC}$ tumor characteristics, associated with higher prediagnostic serum Ca levels [30]. BC makes Ca leak out into the bloodstream from bones, thus elevating its levels in the blood. It may also affect the amount of Ca that the kidneys are able to get rid of. Chemotherapy decreases Ca levels in breast and lung cancer patients probably by reducing PTH related peptide levels [31]. Vitamin D helps in Ca absorption in the intestine in the presence of PTH. If vitamin D is not sufficient for that process to happen Ca not completely absorbed and it causes first hyperthyroidism. Thus, when we use CAF chemotherapy adjunct to vitamin $D$ supplementation it causes Ca be absorbed more in bone and increase BMD, which is in line with our findings shown in Figure 1. Vitamin $D$ is needed for the body to take in phosphate. Vitamin D and PTH regulate phosphate metabolism, it is suggested that they are both related to cancer incidence thus, their abnormal levels may be responsible for the association between phosphate and 
Mohamed et al., Breast Cancer Reports 2019,

cancer risks [32,33]. Previous studies showed that $\mathrm{P}$ is inversely correlated with BC risk [34].

\section{Conclusions}

Albeit the tremendous progress achieved in BC treatment, it is still the principal cause of cancer death among the female population worldwide. Vitamin $D$ is one of the critical factors for female reproductive health, which may have protective effects against many cancer types, including $B C$. In the present study, we found that vitamin $D[25(\mathrm{OH}) \mathrm{D}]$ has decreased the risk of $B C$ recurrence by lowering serum levels of tumor marker CA15-3 and some associated risk factors like body weight and PTH, ALP, and Ca to normal levels, thus increasing segmental and total BMD and decreasing the risk of osteoporosis.

\section{List of Abbreviations}

25(OH)D: Vitamin D

ALP: Alkaline Phosphatase

ANOVA: Analysis of Variance

BC: Breast Cancer

BMD: Bone Mineral Density

BMI: Body Mass Index

CA15-3: Tumor Marker CA15-3

Ca: Calcium

CAF: Cyclophosphamide, Adriamycin, and 5-Fluorouracil

DXA: Dual-energy X-ray Absorptiometry

NMBC: Non-Metastatic Breast Cancer

$P$ : Phosphorus

PTH: Parathyroid Hormone

TNM:Tumor, Node, and Metastases

\section{Competing interests}

The authors declare that they have no competing interests.

\section{Authors' contributions}

\begin{tabular}{|l|c|c|c|c|c|c|}
\hline Authors' contributions & EIM & AMH & NMA & GIK & AMB & NAA \\
\hline Research concept and design & $\checkmark$ & -- & -- & -- & -- & $\checkmark$ \\
\hline Collection and/or assembly of data & $\checkmark$ & $\checkmark$ & $\checkmark$ & -- & -- & $\checkmark$ \\
\hline Data analysis and interpretation & $\checkmark$ & $\checkmark$ & $\checkmark$ & $\checkmark$ & $\checkmark$ & $\checkmark$ \\
\hline Writing the article & $\checkmark$ & $\checkmark$ & $\checkmark$ & -- & -- & $\checkmark$ \\
\hline Critical revision of the article & $\checkmark$ & -- & -- & -- & -- & -- \\
\hline Final approval of article & $\checkmark$ & $\checkmark$ & $\checkmark$ & $\checkmark$ & $\checkmark$ & $\checkmark$ \\
\hline
\end{tabular}

\section{Acknowledgments}

The authors would like to express their deepest gratitude to Mrs. Amira A. Al-Shal, Medical Biophysics Department, Medical Research Institute, Alexandria University, Alexandria, Egypt; for her professional assistance during the follow-up of participant patients.

\section{Publication history}

Editor: Wei-Hsiung Yang, Mercer University School of Medicine, USA.

Received: 22-May-2019 Final Revised: 15-Jun-2019

Accepted: 18-Jun-2019 Published: 25-Jul-2019

\section{References}

1. Alldridge L, Metodieva G, Greenwood C, Al-Janabi K, Thwaites L, Sauven $\mathrm{P}$ and Metodiev M. Proteome profiling of breast tumors by gel electrophoresis and nanoscale electrospray ionization mass spectrometry. J Proteome Res. 2008; 7:1458-69. I Article I PubMed

2. World Health Organization. Cancer. WHO, Geneva. 2019. I Website

3. Khazaei S, Rezaeian S, Khazaei Z, Molaeipoor L, Nematollahi S and Lak P. National breast cancer mortality and incidence rates according to the human development index: an ecological study. Adv Breast Can Res. 2016; 5:30-6.

4. Omar S, Khaled H, Gaafar R, Zekry AR, Eissa S and el-Khatib O. Breast cancer in Egypt: a review of disease presentation and detection strategies. East Mediterr Health J. 2003; 9:448-63. I Pdf I PubMed

5. Ibrahim AS, Khaled HM, Mikhail NN, Baraka H and Kamel H. Cancer incidence in egypt: results of the national population-based cancer registry program. J Cancer Epidemiol. 2014; 2014:437971. | Article | PubMed Abstract | PubMed FullText

6. Abdel-Razeq $\mathrm{H}$ and Awidi A. Bone health in breast cancer survivors. $J$ Cancer Res Ther. 2011; 7:256-63. | Article | PubMed

7. Harris SR. Differentiating the Causes of Spontaneous Rib Fracture After Breast Cancer. Clin Breast Cancer. 2016; 16:431-436. I Article I PubMed

8. Rodriguez-Rodriguez LM, Rodriguez-Rodriguez EM, Oramas-Rodriguez JM, Santolaria-Fernandez F, Llanos M, Cruz J, Martinez A, GonzalezReimers E, Gomez A and Batista N. Changes on bone mineral density after adjuvant treatment in women with non-metastatic breast cancer. Breast Cancer Res Treat. 2005; 93:75-83. I Article I PubMed

9. Datta $M$ and Schwartz GG. Calcium and vitamin D supplementation and loss of bone mineral density in women undergoing breast cancer therapy. Crit Rev Oncol Hematol. 2013; 88:613-24. I Article I PubMed Abstract | PubMed FullText

10. McDonnell SL, Baggerly CA, French CB, Baggerly LL, Garland CF, Gorham ED, Hollis BW, Trump DL and Lappe JM. Breast cancer risk markedly lower with serum 25-hydroxyvitamin D concentrations $>/=60 \mathrm{vs}<20 \mathrm{ng} /$ $\mathrm{ml}$ (150 vs $50 \mathrm{nmol} / \mathrm{L})$ : Pooled analysis of two randomized trials and a prospective cohort. PLoS One. 2018; 13:e0199265. I Article I PubMed Abstract | PubMed FullText

11. Tang C, Chen N, Wu M, Yuan $\mathrm{H}$ and Du Y. Fok1 polymorphism of vitamin $D$ receptor gene contributes to breast cancer susceptibility: a metaanalysis. Breast Cancer Res Treat. 2009; 117:391-9. I Article I PubMed

12. DeLuca HF. Vitamin D. In: Combs GF Jr(Ed.). The vitamins-fundamental aspects in nutrition and health. Amsterdam: Elsevier Academic Press. 2012; 139-78.

13. Kim JY, Lim JE, Jung HH, Cho SY, Cho EY, Lee SK, Yu JH, Lee JE, Kim SW, Nam SJ, Park YH, Ahn JS and Im YH. Validation of the new AJCC eighth edition of the TNM classification for breast cancer with a single-center breast cancer cohort. Breast Cancer Res Treat. 2018; 171:737-745. | Article I PubMed

14. Nicolini A, Ferdeghini M, Colombini $C$ and Carpi A. Evaluation of serum CA549, CA M26 and CA M29 levels in the post-operative follow-up of breast cancer patients. J Nucl Med Allied Sci. 1990; 34:309-13. I PubMed

15. Leary NO, Pembroke A and Duggan PF. Single stable reagent (Arsenazo III) for optically robust measurement of calcium in serum and plasma. Clin Chem. 1992; 38:904-8. I Article I PubMed

16. Burtis CA, Ashwood ER and Bruns DE. TietzTexbook of clinical chemistry and molecular diagnostics. $4^{\text {th }}$ Ed. St. Louis: Elsevier Saunders Company. 2006.

17. Carter GD, Carter CR, Gunter E, Jones J, Jones G, Makin HL and Sufi S. Measurement of Vitamin D metabolites: an international perspective on methodology and clinical interpretation. J Steroid Biochem Mol Biol. 2004; 89-90:467-71. | Article | PubMed

18. Casini A, Mohamed El, Gandin C, Tarantino U, Di Daniele N and De Lorenzo A. Predicting bone mineral density of postmenopausal healthy and cirrhotic Italian women using anthropometric variables. Dig Liver Dis. 2003; 35:881-7. | Article | PubMed

19. Mohamed $\mathrm{El}$ and Khalil ES. Bone densitometric analysis in egyptian hemodialysis patients. Int J Biomed Sci. 2008; 4:120-4. I PubMed 
Mohamed et al., Breast Cancer Reports 2019,

\section{Abstract | PubMed FullText}

20. Kirkpatrick LA and Feeney BC. A simple guide to IBM SPSS statistics for version 20.0. Student Ed. Belmont, Calif.: Wadsworth, Cengage Learning. 2013.

21. Lerchbaum $E$ and Obermayer-Pietsch B. Vitamin D and fertility: a systematic review. Eur J Endocrinol. 2012; 166:765-78. | Article | PubMed

22. Atoum $M$ and Alzoughool F. Vitamin D and Breast Cancer: Latest Evidence and Future Steps. Breast Cancer (Auckl). 2017; 11:1178223417749816. | Article | PubMed Abstract | PubMed FullText

23. Lips $P$ and van Schoor NM. The effect of vitamin $D$ on bone and osteoporosis. Best Pract Res Clin Endocrinol Metab. 2011; 25:585-91. | Article | PubMed

24. Chu WG and Ryu DW. Clinical significance of serum CA15-3 as a prognostic parameter during follow-up periods in patients with breast cancer. Ann Surg Treat Res. 2016; 90:57-63. | Article | PubMed Abstract I PubMed FullText

25. Cataisson C, Lieberherr M, Cros M, Gauville C, Graulet AM, Cotton J, Calvo F, de Vernejoul MC, Foley J and Bouizar Z. Parathyroid hormonerelated peptide stimulates proliferation of highly tumorigenic human SV40-immortalized breast epithelial cells. J Bone Miner Res. 2000; 15:2129-39. | Article | PubMed

26. Isowa S, Shimo T, Ibaragi S, Kurio N, Okui T, Matsubara K, Hassan NM, Kishimoto $\mathrm{K}$ and Sasaki A. PTHrP regulates angiogenesis and bone resorption via VEGF expression. Anticancer Res. 2010; 30:2755-67. | Article I PubMed

27. Misra M, Pacaud D, Petryk A, Collett-Solberg PF and Kappy M. Vitamin $D$ deficiency in children and its management: review of current knowledge and recommendations. Pediatrics. 2008; 122:398-417. | Article | PubMed

28. Banseria N, Malik R, Nigam RK, Trichal VK, Shrivastava A and Jain R. Correlation of serum lipid profile, serum calcium, alkaline phosphatase and serum protein with histopathological grading and staging in head and neck cancer. J Evol Med Dent Sci. 2014; 3:1978-86.

29. Keshaviah A, Dellapasqua S, Rotmensz N, Lindtner J, Crivellari D, Collins J, Colleoni M, Thurlimann B, Mendiola C, Aebi S, Price KN, Pagani O, Simoncini E, Castiglione Gertsch M, Gelber RD, Coates AS and Goldhirsch A. CA15-3 and alkaline phosphatase as predictors for breast cancer recurrence: a combined analysis of seven International Breast Cancer Study Group trials. Ann Oncol. 2007; 18:701-8. | Article | PubMed

30. Almquist M, Bondeson AG, Bondeson L, Malm J and Manjer J. Serum levels of vitamin D, PTH and calcium and breast cancer risk-a prospective nested case-control study. Int J Cancer. 2010; 127:2159-68. | Article | PubMed

31. Hassan BA, Yusoff ZB, Hassali MA, Othman SB and Weiderpass E. Impact of chemotherapy on hypercalcemia in breast and lung cancer patients. Asian Pac J Cancer Prev. 2012; 13:4373-8. | Article | PubMed

32. Uemura H, Irahara M, Yoneda N, Yasui T, Genjida K, Miyamoto KI, Aono $T$ and Takeda $E$. Close correlation between estrogen treatment and renal phosphate reabsorption capacity. J Clin Endocrinol Metab. 2000; 85:1215-9. | Article | PubMed

33. Wulaningsih W, Michaelsson K, Garmo H, Hammar N, Jungner I, Walldius G, Holmberg $L$ and Van Hemelrijck M. Inorganic phosphate and the risk of cancer in the Swedish AMORIS study. BMC Cancer. 2013; 13:257. | Article | PubMed Abstract | PubMed FullText

34. AbdElmoneim NA, Mahmoud TI, Rashad M, El-Sayed Y, Abu-Samra N and Anwar M. The role of serum 25-hydroxy vitamin D ionized calcium and phosphorus in breast cancer females: A case-control study. Int J Basic ApplSci. 2015; 4:228-37.

\section{Citation:}

Mohamed EI, Helal AM, Awad NM, Khalil GI, Bayoumi AM and Abd El Moneim NA. A Longitudinal Study for the Effect of Vitamin D Adjunct to Chemotherapy on Non-Metastatic Breast Cancer Patients after Mastectomy. Breast Cancer Rep. 2019; 6:1.

http://dx.doi.org/10.7243/2057-1631-6-1 